\title{
Unnat Bharat Abhiyan, A Government of India Initiative Complementing Service Learning in Engineering
}

\author{
Surendra Bandi ${ }^{1}$, Santosh Madeva Naik ${ }^{2}$ \\ ${ }^{1}$ Department of Computer Science \& Engineering, HITAM, Hyderabad \\ ${ }^{2}$ Department of Mechanical Engineering, HITAM, Hyderabad \\ ${ }^{1}$ surendra.mca@hitam.org \\ ${ }^{2}$ santoshn.mech@hitam.org
}

\begin{abstract}
Education is one of the most important priorities for any country and Government of India has been implementing several initiatives to take education to every part of the nation. Several objectives like increasing literacy rate, improving quality of education, encouraging skillbased education, promoting technical education, supporting innovations, and empowering universities, were on the top list and made a significant progress over the years. The initiatives of the government were generally open for government institutions and premium private institutions. The most important part of education is to stay connected with society. The education curriculum did not offer much scope to connect with society at large. This article brings out the experience of HITAM(Hyderabad Institute of Technology and Management), an engineering college which benefitted from the government initiative "Unnat Bharat Abhiyan"(UBA). HITAM has been a Participating Institution of UBA since 2018. The initiative helped faculty and students to work with society, understand the societal development, know the role of engineer for the society, take up technological interventions and develop products used in the society. This in turn created a platform for students to apply engineering knowledge in real time problems. Being a participating institution, HITAM followed the framework of UBA and adopted five villages, conducted household survey, organized gram sabhas, identified the problems in the adopted villages where technological interventions are required. The proposals for technological interventions were uploaded in UBA portal and were scrutinized by the subject expert groups. The college was sanctioned with the required budget to carryout the projects proposed.
\end{abstract}

\section{Surendra Bandi}

Department of Computer Science \& Engineering, HITAM, Hyderabad

\section{surendra.mca@hitamorg}

More than 100 students took part in the village surveys and 18 students were part of technological interventions. HITAM received fund from the Government for conducting household survey, technological interventions and perennial funding for active involvement in all the UBA activities. The students who were part of the initiative expressed that it was a life changing experience for them towards society and complemented their learning. Servicelearning as a pedagogy was evolved out of the initiative at HITAM, apart from the financial support from the Government.

Keywords: Engineering, Unnat Bharat Abhiyan, Government Initiative, Service-learning

\section{Introduction}

Unnat Bharat Abhiyan (UBA) is an initiative of government of India which was started in 2014 in Indian Institute of Technology (IIT), Delhi, India. IIT, Delhi has been in the news for their work in the space of rural development and appropriate technology. Coordinators of Rural Technology Action Group (RuTAG), several NonGovernmental Organizations (NGOs) and Educational Institutions also have their share of contribution in creating the idea of integrating service and learning. The specific vision of the UBA is to bring transformational change in rural development processes with the support of educational institutions and build the architecture of an inclusive India. The mission of the UBA is to sensitize the educational institutions to work with society, understand the challenges, develop capabilities to meet the needs of emerging professions. Different possible options to be stakeholders of UBA are as a prospective mentoring institution, as a participating institute, as a subject expert, as a voluntary organization, as a developmental agency, as a philanthropist, as a CSR(Corporate Social Responsibility) promotor, as an NSS(National Service Scheme) Member, as an enthusiastic volunteer. (Introduction: Unnat Bhart Abhiyan, Governmnet of India's Initiative, 2014).

Service-learning is a teaching strategy in which academic learning objectives are met while the meaningful service takes place with enhanced civic responsibility. Students learn and develop through the activities that are planned around the needs of community. They experience while take part in the community engagement interventions. They write their reflections and create a scope for personal, intellectual and social growth. (Duckenfield \& Swanson, 1992). Quality assurance agencies of engineering education have included softer skills as one of the essential requirements in the curriculum to be given priority. (Edmund Tsand, 2001). Practitioners of service-learning 
have provided several guidelines on the myths while implementing the pedagogy for learning. Teachers can implement few of he principles in their curriculum in a phased manner instead of attempting all at a time. (Anderson, 2001). Community service-learning projects are meant for acquisition of various skills, knowledge and attitudes that meet the academic assessment requirements too. (Scharrer, 2006). The value added through servicelearning pedagogy in terms of achieving higher cognitive levels is witnessed in several programs. (ANGELA R. BIELEFELDT, 2010).

\section{Methodology}

The Participating Institutions of UBA are given certain guidelines to implement service-learning on behalf of the institution to ensure inclusive societal development. There is a set hierarchy for all the stakeholders to be associated in the program and add their respective parts.

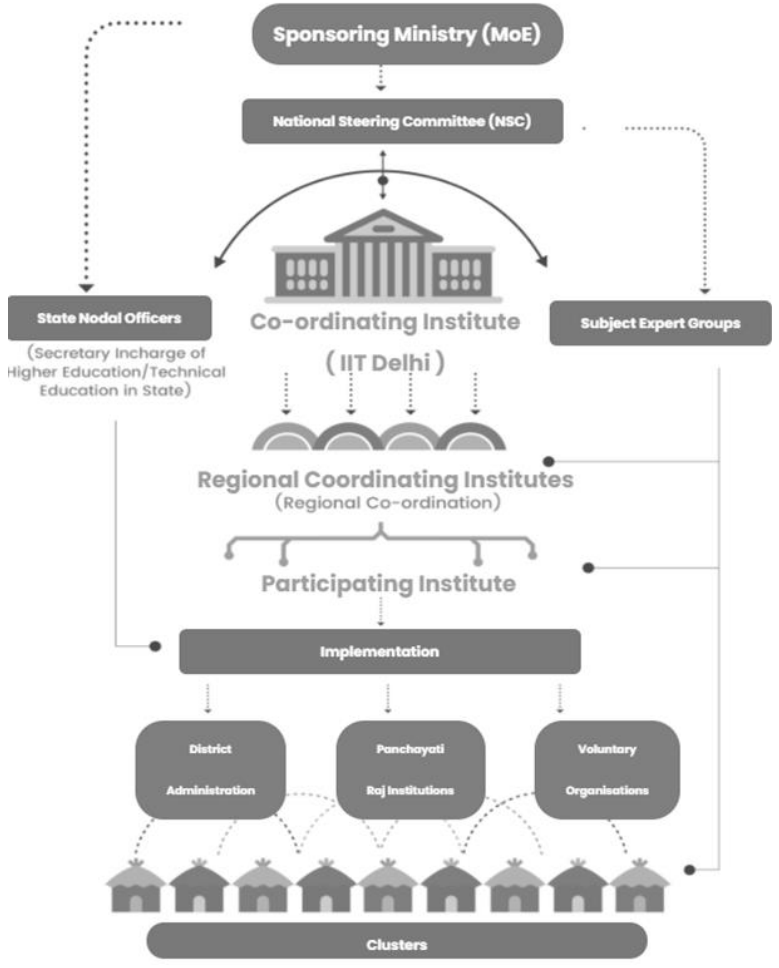

Fig. 1 UBA Framework of Activities

The hierarchy of the UBA Framework for involvement of educational institutions in societal development starts with Ministry of Education on the top,

National Steering Committee to take policy decisions and review the program regularly and make changes as required, National Coordinating Institute is responsible for complete implementation of the scheme by coordinating with all the stakeholders and particularly with the support of Regional Coordinating Institutes in the respective states, State Nodal Officers who ensure giving weightage for the program organized under the scheme, Subject Expert Groups play a critical role in evaluating technical proposals received, Regional Coordinating Institutes monitor the progress of the work carried out by the Participating Institutes and train the faculty to plan activities related to community engagement, Participating Institutes are the educational institutions who are supposed to work with nearby villages in the given framework and connect villages with the students, Representatives of Districts, Panchayats and Volunteer Organizations play their role by supporting the students in learning and social innovations

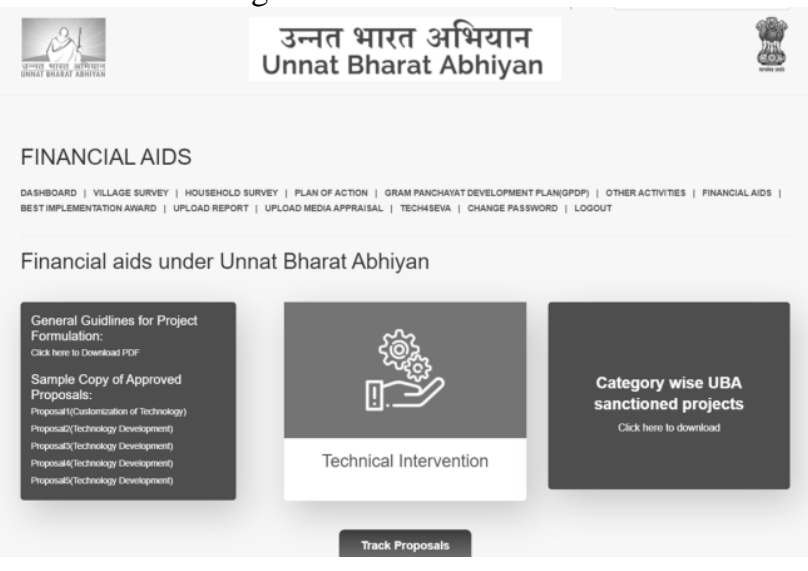

Fig. 2 Option to submit proposals for Technical Interventions in UBA Portal login of PI

HITAM being an engineering institution, applied to become a Participating Institute in UBA in 2018 and was approved to be a PI. The functions of a PI are to adopt villages, conduct village survey, household survey, plan of action, gram panchayat development plan and involve in technological interventions in the villages. The process followed for adopting a village is to be carried out by the coordinator from the PI. The coordinator identifies a suitable village near the institution where the students can be part of understanding various aspects of the village. The same has to be briefed to the officials of the respective panchayats and a proposal has to be made to the collector of the district to adopt the village under UBA Scheme. The district collector would approve it and updates in the records. The approval letter can be sent to UBA Regional and National Coordinating Institutes to get added to the PI portal. Once the NCI approves the adoption of the village, the details reflect in the PI's portal. PI can take up the village survey as the first step. Village survey needs the basic details of the villages which are collected from the village officials. Once the village survey is completed, students are required to carry the household survey forms to the village and conduct the survey.

The household survey intends to collect the data like all the demographic information, gender wise population across age groups, Poverty line across prevailing caste section, Aadhar coverage, Bank and Government Schemes coverage, Migration Scenario, Basic Amenities like Education, Literacy, Health, Access to drinking water, Drainage facility and Sanitation, Compost pits, Households with and without toilets, Type of houses, Village connectivity, Village infrastructure, Land type, Land use pattern, Irrigation sources, Forest and horticulture profile, Use of chemicals and fertilizers, Agriculture produce, Livestock 
assets, Cattle population, Occupation pattern, Income analysis, Source of energy and power, Usage of cooking fuels. Faculty and students are expected to explore the survey forms which gives an idea of the livelihood and resources of the village in general.

Once the data is collected, the participating institution gets to know and see various dimensions of the society. Students will have access to live problems to apply their engineering knowledge and improve their learning. Students of HITAM were part of adopting five villages and conducted village survey and household survey. They also have developed plans for gram panchayats. Some of the batches of the students have submitted proposals under development of technologies which simplifies the life in the village and was funded by the UBA to deploy those solutions. Fund for enhancement of solutions was also granted. The same is shown in the Figure 2. The role of Subject Expert Group in the hierarchy is to evaluate the proposals submitted by the students. They raise queries on the proposals to make them more meaningful which create scope for utility for the community but not creating any individual assets.

The systematic approach of the UBA framework allowed students to covert their proposals into their academic projects and get credits while they support community with the products completed. Several workshops have been organized for faculty to empower them to guide students in social engagement.

\section{Results}

HITAM adopted seven villages from 2018 and has been continuing to work with them involving students in understanding the society. Details of the villages adopted by HITAM are shown in the Figure 3. The Coordinator visited the respective villages, explained the concept of involving students in the societal development. Details of the key people from the village are gathered and same was also updated in the UBA Portal in the PI's login.

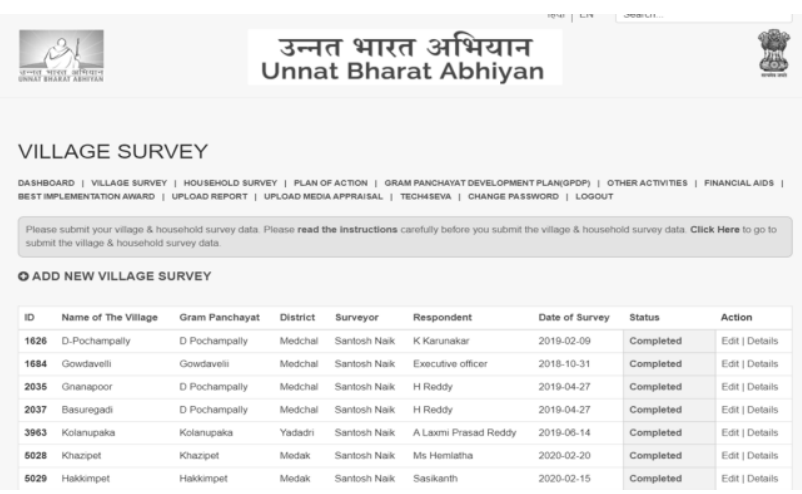

Fig. 3 Option of adding a new village in the UBA Portal login of PI
Plan of actions for the adopted villages have been done by the students by considering the feasibility of dealing with the respective problems. The same is updated on the UBA portal as shown in Figure 4.

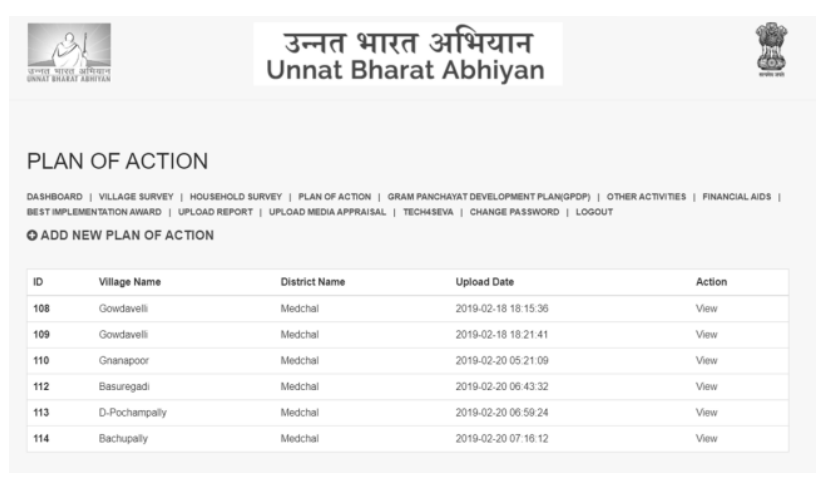

Fig. 4 Plan of Actions Uploaded by HITAM

Students also made a gram panchayat development plan which involves the scope of continuous engagement with the community including the transition of batches of students. NGOs(Non-Governmental Organizations) of the villages have been considered to be the most influential stakeholders who could act as a continuous supporter in bridging the gaps during the transitions from one batch of students to another batch. Students of HITAM made such plans for four of the villages adopted which is shown in the Figure 5.

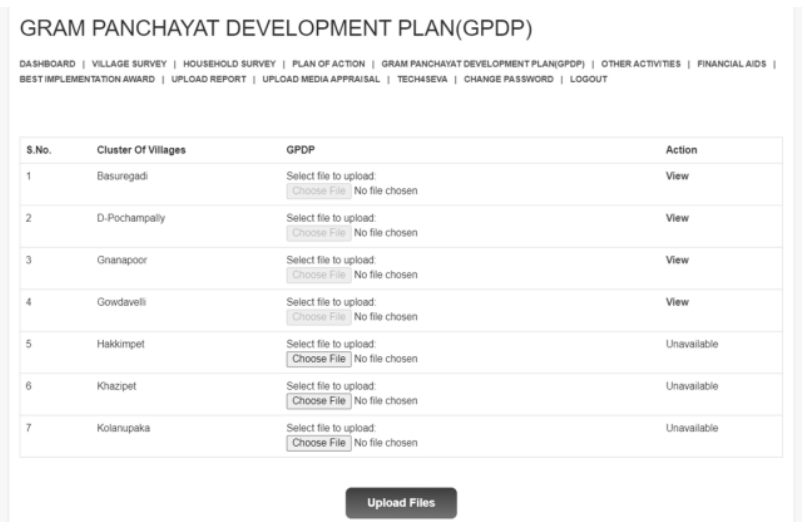

Fig. 5 GPDPs Uploaded by HITAM

After the household data is collected, students were able to see huge scope of diversified problem statements which fit into their area of interest to work. All the batches of students have come up with technical proposals to work with community in creating products such as fertilizer sprayers, water purifiers, water pulling pumps, smart dust bins, solar water pool skimmers, grass cutters, cow dung removers, seed sowers, smart water irrigation system and etc. Such one proposal is shown in the Figure 6.

Three projects have been funded by the UBA. Besides funding, students have participated in several innovation competitions and won the awards. The story of HITAM as a participating institute has been published in the UBA 
report in 2019. Around 100 students have expressed that their confidence has been significantly increased after they were part of UBA activities at HITAM. Details of the students who benefited from the UBA activities is given in the Table 1.

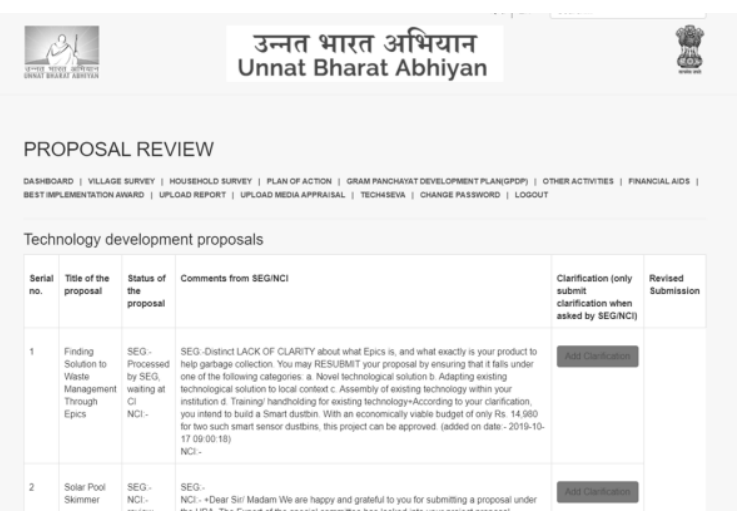

Fig. 6 Sample of the Proposal which is being reviewed by SEG

Table 1. Number of students participating in UBA Activities

\begin{tabular}{|l|c|}
\hline Activity & Number of Students \\
\hline Conducting Survey & 60 \\
\hline Participating in Gramsabhas & 14 \\
\hline $\begin{array}{l}\text { Participating in Vishwakarma } \\
\text { Awards }\end{array}$ & 18 \\
\hline Innovative Projects Ideas & 6 \\
\hline State Innovation Projects & 12 \\
\hline Technological Interventions & 15 \\
\hline Rural Innovation Start Up & 3 \\
\hline
\end{tabular}

\section{Discussion}

Social immersion scope is extremely high in the local service projects. (Gregory Bixler, 2014). Conscious spending of time in the community inquiring the details which are critical for cultural, economic and technical development of the nation is needed to see the possible areas of applications of engineering. Based on the reflections of the students, engineering educators should be encouraged to used service-learning as a pedagogy for acquiring professional life skills. (Adam Carberry, 2013)

Technological interventions create scope for students to deeper understanding of the engineering problems. The initiative also helps in building civic responsibility and ethical thinking in the students. Macro ethical issues can be taught to the students using Learning Through Service (LTS). (Angela R. Bielefeldt, 2016). Financial support is the greatest motivation for the educational institutions and students to spend time on the social interventions while applying the concepts learnt in the classroom. Skill development with these interventions as pedagogies would lead to creation of wealth and improving quality of lives.

\section{Conclusion}

The initiative helped all the stakeholders in accomplishing their respective objectives. The vision of indigenous and inclusive development of society with the involvement of educational institutions is being accomplished. The funding allocated by the government for such activities further boosted the motivation of the students and teachers. It was also witnessed that the learning was complemented by the activities under UBA. The college was able to leverage the government scheme to introduce understanding the role of engineers for society. Further study is recommended on integrating such initiatives meaningfully into curriculum by the way of academic projects and incentivising with significant credits and creating more socially useful engineers in India.

\section{Acknowledgements}

My sincere thanks to the team of XPLORE (Experiential Learning in Outreach \& Realtime Engineering) Center at HITAM for their support in providing right data at all times. Promotors of HITAM deserve appreciations for their vision of preparing engineers to become confident and contribute to society The vision of HITAM created scope for the students to experience service learning and build life skills along with professional \& technical skills.

\section{References}

Adam Carberry, H.-S. L. (2013). Student Perceptions of Engineering Service Experiences as a Source of Learning Technical and Professional Skills. 8(1).

Anderson, J. B. (2001). PRINCIPLES OF GOOD PRACTICE FOR SERVICE-LEARNING IN PRESERVICE TEACHER EDUCATION . In D. Hill, Principles of Good Practice for ServiceLearning in Preservice Teacher Education. Omaha: DigitalCommons@UNO.

ANGELA R. BIELEFELDT, K. G. (2010). Measuring the Value Added from Service Learning in ProjectBased Engineering Education. 26(3), 535-546.

Angela R. Bielefeldt, N. C. (2016). Contributions of Learning through Service to the Ethics Education of Engineering Students. 11(2).

Duckenfield, M., \& Swanson, L. (1992). Service Learning: Meeting the Needs of Youth At Risk. A Dropout Prevention Research Report. Clemson, SC.: National Dropout Prevention Center, Clemson, SC.

Edmund Tsand, J. V. (2001). A Report on Service-Learning and Engineering Design: Service-Learning's Effect on Students Learning Engineering Design in 'Introduction to Mechanical Engineering'. 17(1).

Gregory Bixler, J. C. (2014). Humanitarian Engineering at The Ohio State University: Lessons Learned in Enriching Education While Helping People. Special Edition.

Introduction: Unnat Bhart Abhiyan, Governmnet of India's Initiative . (2014, November 11). Retrieved from Unnat Bhart Abhiyan, Governmnet of India's Initiative: https://unnatbharatabhiyan.gov.in:8443/introductio $\mathrm{n}$

Scharrer, L. C. (2006). Assessing Learning in Community Service Learning: A Social Approach. 13(1). 